\title{
Development and Validation of a Discriminating In Vitro Dissolution Method for Oral Formulations Containing Satranidazole
}

\author{
Harshal Ashok Pawar and Pooja Rasiklal Joshi \\ Dr. L. H. Hiranandani College of Pharmacy, Smt. CHM Campus, Ulhasnagar, Maharashtra 421003, India \\ Correspondence should be addressed to Harshal Ashok Pawar; harshal.dlhhcop@gmail.com
}

Received 2 January 2014; Accepted 27 March 2014; Published 24 April 2014

Academic Editor: Hakan Arslan

Copyright (C) 2014 H. A. Pawar and P. R. Joshi. This is an open access article distributed under the Creative Commons Attribution License, which permits unrestricted use, distribution, and reproduction in any medium, provided the original work is properly cited.

\begin{abstract}
The development of a meaningful dissolution procedure for drug products with limited water solubility has been a challenge to the pharmaceutical industry. Satranidazole (BCS Class II drug) is a new nitroimidazole derivative with potent antiamoebic action. There is no official dissolution medium available in the literature. In the present study, parameters such as saturation solubility in different $\mathrm{pH}$ medium, dissolution behavior of formulations, influence of sink conditions, stability, and discriminatory effect of dissolution testing were studied for the selection of a proper dissolution medium. Results of solubility data revealed that solubility of Satranidazole decreases with an increase in $\mathrm{pH}$. Satranidazole showed better sink condition in $0.1 \mathrm{~N} \mathrm{HCl}$ as compared to other media. The drug and marketed formulations were stable in the dissolution media used. An agitation speed of $75 \mathrm{rpm}$ showed a more discriminating drug release profile than $50 \mathrm{rpm}$. Using optimized dissolution parameters (paddle at $75 \mathrm{rpm}, 900 \mathrm{~mL} 0.1 \mathrm{~N}$ $\mathrm{HCl})$ greater than $80 \%$ of the label amount is released over 60 minutes. UV-spectroscopic method used was validated for the specificity, linearity, precision, robustness, and solution stability. The method was successfully applied to granular formulations and also to marketed tablets containing $300 \mathrm{mg}$ Satranidazole.
\end{abstract}

\section{Introduction}

Satranidazole (STZ) is a new nitroimidazole derivative with potent antiamoebic action. It is used in the treatment of intestinal and hepatic amoebiasis, giardiasis, trichomoniasis, and anaerobic infections. Its dose is $300 \mathrm{mg}$ twice daily for 3-5 days in the treatment of amoebiasis and $600 \mathrm{mg}$ as a single dose in the treatment of giardiasis and trichomoniasis. It is reported that Satranidazole exhibits significantly higher plasma concentrations than metronidazole and has a plasma elimination half-life of $1.01 \mathrm{~h}$ which is significantly shorter than the corresponding metronidazole half-life of $3.62 \mathrm{~h} \mathrm{[1]}$. Also Satranidazole is having better tolerability, absence of neurological and disulfiram like reactions, and it can be preferred in patients with susceptible neurological symptoms [2].

Dissolution study is particularly important for insoluble or low solubility drugs where absorption is dissolution rate limited. The incorporation of adjuvants (e.g., diluents, lubricants, and surfactants) into the formulation of a solid oral dosage form can cause significant effects on the dissolution rate of drugs, especially those that are hydrophobic and poorly soluble [3]. In the case of Class 2 drugs in the Biopharmaceutics Classification System (BCS), dissolution may be the rate-limiting step for drug absorption, so suitable dissolution tests can be used to predict differences in bioavailability among different formulations [4]. The choice of formulation is often of critical importance in establishing a successful product for oral administration of this class of drugs [5]. In this context, the purpose of the present study was to evaluate and compare the dissolution profiles of a compounded formulation to that of a marketed product using Satranidazole as a model drug. This drug is poorly soluble in water and has high in vitro permeability; it is therefore classified as BCS Class II [6]. To date, there is no published dissolution test for the evaluation of in vitro release profiles 
of this drug from immediate-release solid oral dosage forms. The objective of the present study was to develop a validated in vitro dissolution method for oral granular formulation containing Satranidazole.

\section{Materials and Methods}

2.1. Materials. Satranidazole was obtained as a gift sample from Alkem Laboratories, Mumbai. Eudragit E100 was obtained from Evonik Degussa, Mumbai. Satrogyl tablets (strength: $300 \mathrm{mg}$ ) were purchased from market. All the chemicals and reagents used were of analytical grade.

\subsection{Formulation Development of Taste Masked STZ Granules.} Two different batches of taste masked granules of STZ were formed by melt granulation technique using stearic acid and Eudragit EPO using different ratio of drug to stearic acid. The composition of the compounded formulation is mentioned below.

Product A. It is labeled to contain $300 \mathrm{mg}$ of the drug and the following excipients: stearic acid, Eudragit EPO, starch 1500, magnesium oxide, mannitol, xylitol, sodium carboxymethyl cellulose, hydroxypropyl cellulose, vanilla, aspartame, and magnesium stearate with drug to stearic acid ratio $(1: 2)$.

Product B. It islabeled to contain $300 \mathrm{mg}$ of the drug and the same above mentioned excipients with different drug to stearic acid ratio $(1: 1.5)$.

The assay of the above two products was performed using previously developed and validated HPLC method, and the contents results were used to calculate the percentage release on each time of dissolution profile. These two products were used to study the discriminatory power of developed method.

2.3. Instrumentation. Dissolution test was performed in an Electrolab dissolution test system (TDT-08L), in accordance with USP Pharmacopoeia general method. A double-beam UV-Vis spectrophotometer (Shimadzu 1800, Japan) with $1.0 \mathrm{~cm}$ quartz cells was used for all absorbance measurements. All the absorbances were carried out at a UV wavelength of $320 \mathrm{~nm}$.

2.4. Saturation Solubility Study. The saturation solubility of Satranidazole was determined in $\mathrm{pH} 1.2(0.1 \mathrm{~N} \mathrm{HCl}), 2.1$ (0.01 N HCl), 4.5 (acetate buffer), 6.8 (phosphate buffer), 7.4 (phosphate buffer), and distilled water at $37^{\circ} \mathrm{C}$. Excess STZ was added to $100 \mathrm{~mL}$ of dissolution medium in a conical flask and agitated continuously at room temperature for $8 \mathrm{~h}$ on a shaker. The solutions were kept aside for $1 \mathrm{~h}$ until equilibrium was achieved. The solutions were then filtered through no. 41 Whatman filter paper, and the filtrate was suitably diluted and analyzed spectrophotometrically at $320 \mathrm{~nm}$.

2.5. Determination of Sink Conditions and Dissolution Conditions. For poorly soluble drugs, medium selection for dissolution tests is an important step in method validation due to the difficulty to achieve sink condition [7], which is defined as the volume of medium at least three times greater than that required to dissolve the dose of the drug being tested [8].

Sink condition was determined using following equation:

$$
\text { Maximum Dissolvable Dose }=V \times \frac{C_{S}}{\operatorname{Sink}},
$$

where

$$
\begin{aligned}
& V \text { = Dissolution medium volume, } \\
& C_{S}=\text { Saturated solubility of the compound in the } \\
& \text { medium, } \\
& \text { Sink = Sink condition factor. }
\end{aligned}
$$

From preselected, $0.1 \mathrm{~N} \mathrm{HCl}$ media, dissolution testing was performed on granules $(n=6)$ in compliance with USP $<1092>$ using paddle (USP-II). The discriminatory power of the dissolution method was assessed by analyzing two inhouse developed granular formulations of STZ (coded as products $\mathrm{A}$ and $\mathrm{B}$ ) of $300 \mathrm{mg}$ strength prepared by using different composition of excipients. Product A contains $600 \mathrm{mg}$ stearic acid as a disintegrant whereas product $B$ contains $450 \mathrm{mg}$ stearic acid. Other excipients in both products were the same.

The dissolution rate of STZ from granules of product A was assessed at 50 and $75 \mathrm{rpm}$, the recommended speeds for USP apparatus II. At $75 \mathrm{rpm}$, product A exhibited a very rapid dissolution without coning.

A calibrated dissolution apparatus (USP II) was used with paddle at $75 \mathrm{rpm}$ and bath temperature maintained at $37 \pm$ $0.5^{\circ} \mathrm{C}$. Nine hundred millilitre freshly prepared $0.1 \mathrm{~N} \mathrm{HCl}$ solution was used as the dissolution medium. Dissolution samples were collected at $10,15,30,45$, and $60 \mathrm{~min}$ for immediate-release granules (products A and B) and replaced with an equal volume of the fresh medium to maintain a constant total volume. After the end of each test time, samples aliquots were filtered, diluted in dissolution medium, when necessary, and were analyzed by UV at $320 \mathrm{~nm}$. At each time point, a $5 \mathrm{~mL}$ sample was removed from each vessel and filtered into labeled glass tubes, diluted and analyzed by UV at $320 \mathrm{~nm}$. The dissolution of marketed formulation was also carried out in same conditions. The \% cumulative release of drug was calculated using standard calibration curve of STZ prepared in $0.1 \mathrm{~N} \mathrm{HCl}$.

2.6. Comparison of Dissolution Profiles by a Model-Independent Method. The in vitro dissolution data of products A and B was compared by two-tailed Student's $t$-test. Moore and Flanner proposed a model-independent mathematical approach to compare the dissolution profile using two factors, $f_{1}$ and $f_{2}[9]$ :

$$
\begin{aligned}
& f_{1}=\left\{\frac{\left[\sum_{t=1}^{n}\left|R_{t}-T_{t}\right|\right]}{\left[\sum_{t=1}^{n} R_{t}\right]}\right\} \times 100, \\
& f_{2}=50 \times \log \left\{\left[1+\left(\frac{1}{n}\right) \sum_{t=1}^{n}\left(R_{t}-T_{t}\right)^{2}\right]^{-0.5} \times 100\right\},
\end{aligned}
$$

where $R_{t}$ and $T_{t}$ are the cumulative percentage dissolved at each of the selected $n$ time points of the reference and 
test product, respectively. The factor $f_{1}$ is proportional to the average difference between the two profiles, whereas factor $f_{2}$ is inversely proportional to the average squared difference between the two profiles, with emphasis on the larger difference among all the time points. The factor $f_{2}$ measures the closeness between the two profiles. Because of the nature of measurement, $f_{1}$ was described as difference factor and $f_{2}$ as similarity factor [10]. FDA has set a public standard of $f_{2}$ value between 50 and 100 to indicate similarity between two dissolution profiles.

2.7. Analytical Method Validation. UV-spectroscopic method used for estimation of Satranidazole in dissolution samples was validated by determining the specificity, linearity, precision, robustness, and solution stability according to USP and ICH guidelines [11-13]. The standard solution containing $25 \mu \mathrm{g} / \mathrm{mL}$ of Satranidazole in $0.1 \mathrm{~N} \mathrm{HCl}$ was scanned between 200 and $400 \mathrm{~nm}$ to determine the $\lambda$ max using $0.1 \mathrm{~N} \mathrm{HCl}$ as blank in UV spectrophotometer (Shimadzu 1800).

2.7.1. Specificity. Placebo batch of the granules was prepared in its usual concentration. Dissolution was performed similarly as that of the STZ granules in $900 \mathrm{~mL}$ of $0.1 \mathrm{~N} \mathrm{HCL}$ as dissolution medium using USP apparatus II at $37 \pm 0.5^{\circ} \mathrm{C}$ at $75 \mathrm{rpm}$ for $1 \mathrm{hr}$. Aliquots of this solution were filtered, diluted appropriately, and analyzed by UV spectrophotometric method.

2.7.2. Linearity. Stock solution of $1000 \mathrm{ppm}$ was prepared by dissolving $50 \mathrm{mg}$ drug in $50 \mathrm{~mL}$ methanol. From this 2nd stock solution of $100 \mathrm{ppm}$ was prepared in $0.1 \mathrm{~N}$ HCL. Further dilutions were carried out to give solutions of 2, 4, $6,8,10,15,25$, and $30 \mu \mathrm{g} / \mathrm{mL}$. 0.1 N HCL was used as blank and absorbances of prepared solutions were noted at $320 \mathrm{~nm}$ and calibration curve was constructed. Each solution was prepared in triplicate.

2.7.3. Recovery/Accuracy. A recovery study was carried out by adding granules equivalent to 80,100 , and $120 \%$ of drug in the dissolution vessel. The dissolution test was done for $60 \mathrm{~min}$ using $900 \mathrm{~mL}$ of dissolution $0.1 \mathrm{~N} \mathrm{HCL}$, apparatus 2 rotating at $75 \mathrm{rpm}$. Aliquots of $5 \mathrm{~mL}$ were filtered with quantitative filter and analyzed by UV spectrophotometric method at the final concentrations $13.3,16.6$, and $20 \mu \mathrm{g} / \mathrm{mL}$, respectively. Each concentration was prepared in duplicate and each one was analyzed in triplicate [14].

2.7.4. Method Precision/Repeatability. It was performed on 6 doses of granules from same batch and samples were analyzed according to the test method and aliquots were taken at the end of 60 minutes [15].

Intermediate precision was evaluated to determine the effects of random events on the precision of the analytical procedure. This was done by performing the dissolution on same batch of granules on different day by changing the analyst.
TABLE 1: pH dependent solubility of Satranidazole in different buffer solutions.

\begin{tabular}{lcc}
\hline $\mathrm{pH}$ & Solubility $(\mathrm{mg} / \mathrm{mL})^{*}$ & Sink condition \\
\hline $1.2(0.1 \mathrm{~N} \mathrm{HCl})$ & 1.5125 & 4.5375 \\
$2.1(0.01 \mathrm{~N} \mathrm{HCl})$ & 1.1985 & 3.5955 \\
4.5 (acetate buffer) & 0.9813 & 2.9439 \\
6.8 (phosphate buffer) & 0.8251 & 2.4753 \\
7.4 (phosphate buffer) & 0.9825 & 2.9475 \\
Distilled water & 0.8133 & 2.4399 \\
\hline
\end{tabular}

${ }^{*}$ Mean of 3 determinations.

2.7.5. Robustness. Robustness was studied by changing the wavelength of UV spectrophotometer at $320 \pm 2 \mathrm{~nm}$ and also by changing agitation rate of dissolution apparatus at $75 \pm$ $2 \mathrm{rpm}$.

2.7.6. Solutions Stability. To evaluate solution stability, the sample solution was stored at room temperature and was analyzed by UV spectrophotometer for $24 \mathrm{hrs}$ at various time intervals.

\section{Results and Discussions}

For immediate-release formulations, apparatus 1 (baskets) at $100 \mathrm{rpm}$ or apparatus 2 (paddles) at 50 or $75 \mathrm{rpm}$ is most commonly used. Other agitation speeds and apparatus are acceptable with appropriate justification. For dosage forms that exhibit coning (mounding) under the paddle at $50 \mathrm{rpm}$, the coning can be reduced by increasing the paddle speed to $75 \mathrm{rpm}$, thus reducing the artifact and improving the data.

Reference compendia and guidelines of Food Drug Administration, United States Pharmacopeia, Federation International Pharmaceutique, World Health Organization, European Pharmacopoeia, and Japanese Pharmacopoeia recommend the use of rotating paddle between 50 and $100 \mathrm{rpm}$ with volume of 500 to $1000 \mathrm{~mL}$ along with surfactant to provide sink condition for insoluble drug products [16].

The most common way to check the discriminatory power of the method is to test formulations with differences resulting forms, changes in the characteristics of the API, drug product composition, product manufacturing process, and stability conditions [10, 17-19].

Drug solubility and solution stability are important properties to be considered when selecting the dissolution medium. From the saturation solubility data and established sink conditions (Table 1), it was found that $\mathrm{pH} 1.2$ (0.1 N HCL) was better dissolution medium for Satranidazole.

The solution stability data is represented in Table 2 . The solution of drug was found to be stable in $0.1 \mathrm{~N} \mathrm{HCL}$ for 24 hours. The cumulative \% RSD obtained was less than 2 at the end of $24 \mathrm{hrs}$.

The stirring speeds of $50 \mathrm{rpm}$ and $75 \mathrm{rpm}$ for product A were tested. The statistical Student $t$-test was applied to compare the percent drug release, using 50 or $75 \mathrm{rpm}$ for granules (Table 3 ). The $P$ value for granules was smaller than the delineated significance level, indicating that there is statistically significant difference between the drug release 
TABLE 2: Stability data in 0.1 N HCL.

\begin{tabular}{lcccc}
\hline Time & Absorbance & Mean & SD & \% RSD \\
\hline 30 minutes & 0.757 & - & - & - \\
$1 \mathrm{hr}$ & 0.758 & 0.7575 & 0.00071 & 0.093 \\
$2 \mathrm{hrs}$ & 0.752 & 0.75567 & 0.00321 & 0.425 \\
$4 \mathrm{hrs}$ & 0.759 & 0.7565 & 0.00311 & 0.411 \\
$8 \mathrm{hrs}$ & 0.745 & 0.7542 & 0.00581 & 0.770 \\
$16 \mathrm{hrs}$ & 0.734 & 0.75083 & 0.00975 & 1.298 \\
$24 \mathrm{hrs}$ & 0.745 & 0.75 & 0.00917 & 1.222 \\
\hline
\end{tabular}

TABle 3: Product A dissolution tests results $(n=12)$, using different stirring speeds and $\mathrm{HCl} 0.1 \mathrm{~N}$ as dissolution medium.

\begin{tabular}{lcccc}
\hline \multirow{2}{*}{ Time in minutes } & \multicolumn{2}{c}{ \% Cumulative release } & t-test & $P$ \\
& $50 \mathrm{rpm}$ & $75 \mathrm{rpm}$ & & \\
\hline 0 & 0 & 0 & & \\
5 & 5.91 & 8.65 & & \\
10 & 17.57 & 33.15 & & \\
15 & 39.62 & 45.29 & 4.4858 & 0.0065 \\
30 & 45.88 & 66.67 & & \\
45 & 60.43 & 76.48 & & \\
60 & 71.38 & 87.59 & & \\
\hline
\end{tabular}

TABLE 4: Comparison of dissolution profile of two products (A and B) with different ratio of drug : stearic acid.

\begin{tabular}{lcc}
\hline Time (minutes) & $\begin{array}{c}\text { Product A } \\
\text { Drug: stearic acid } \\
(1: 2)\end{array}$ & $\begin{array}{c}\text { Product B } \\
\text { Drug: stearic acid } \\
(1: 1.5)\end{array}$ \\
\hline 0 & 0 & 0 \\
5 & $8.71 \pm 0.426$ & $8.02 \pm 0.512$ \\
10 & $33.9 \pm 0.299$ & $52.99 \pm 0.69$ \\
15 & $46.05 \pm 0.343$ & $62.68 \pm 0.489$ \\
30 & $65.83 \pm 0.378$ & $73.40 \pm 0.397$ \\
45 & $78.57 \pm 0.418$ & $81.66 \pm 0.434$ \\
60 & $87.65 \pm 0.404$ & $90.01 \pm 0.546$ \\
Similarity factor $f_{2}$ & & 46 \\
Difference factor $f_{1}$ & & 17 \\
\hline
\end{tabular}

TABLE 5: Linearity data.

\begin{tabular}{lc}
\hline Concentration $($ in $\mathrm{mcg} / \mathrm{mL})$ & Absorbance \\
\hline 2 & 0.0822 \\
4 & 0.1433 \\
6 & 0.2175 \\
8 & 0.2793 \\
10 & 0.3398 \\
15 & 0.5057 \\
20 & 0.6301 \\
25 & 0.7518 \\
30 & 0.9204 \\
\hline
\end{tabular}

percent, and suggested that the stirring speed of $75 \mathrm{rpm}$ is better than $50 \mathrm{rpm}$.

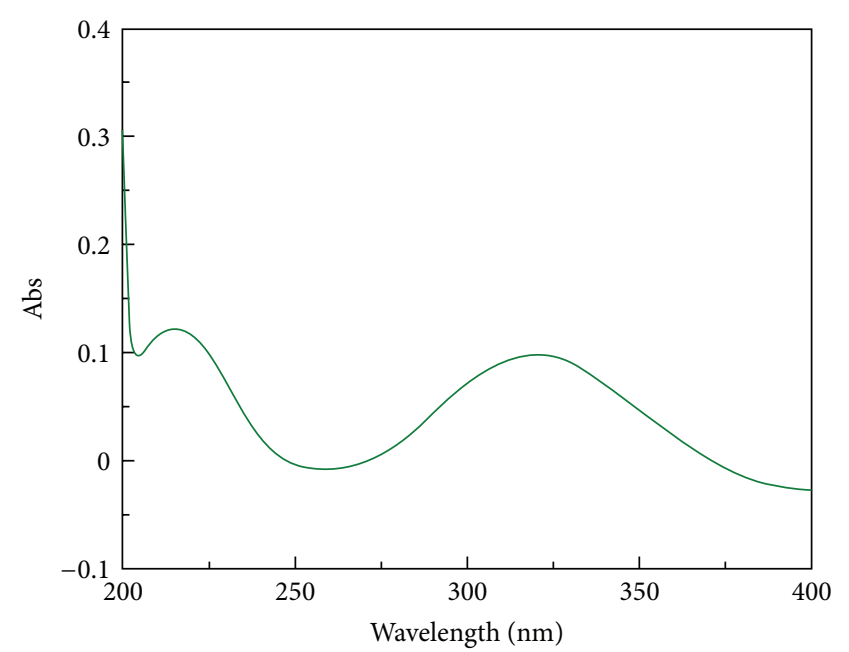

FIGURE 1: UV spectrum of STZ in $0.1 \mathrm{~N} \mathrm{HCl}$.

TABLE 6: Results of accuracy.

\begin{tabular}{lcccc}
\hline $\begin{array}{l}\text { Added } \\
\text { amount }(\mu \mathrm{g})\end{array}$ & $\begin{array}{c}\text { Recovered } \\
\text { amount }(\mu \mathrm{g})\end{array}$ & Recovery* (\%) & Mean (\%) & \% RSD \\
\hline $13.3(80 \%)$ & 12.93 & $97.21 \pm 1.2430$ & & \\
$16.6(100 \%)$ & 16.46 & $99.15 \pm 1.3256$ & 99.1133 & 1.90 \\
$20(120 \%)$ & 20.196 & $100.98 \pm 1.5234$ & & \\
\hline
\end{tabular}

${ }^{*}$ Each value is the mean of 3 determinations.

On comparison of dissolution of products $\mathrm{A}$ and $\mathrm{B}$ the $f_{1}$ value was found to be 46 and $f_{2}$ value was found to be 17 as shown in Table 4, indicating dissimilarity between products $\mathrm{A}$ and B. It can be concluded that the drug release profile at $75 \mathrm{rpm}$ detected small changes in drug product composition.

The $\lambda$ max was found to be $320 \mathrm{~nm}$ in dissolution medium and hence it was taken as the analytical wavelength. The UV spectrum of STZ in $0.1 \mathrm{~N} \mathrm{HCl}$ is shown in Figure 1.

3.1. Specificity. It was found that dissolution of placebo was having no effect on dissolution of Satranidazole granules. Also the excipients used for the formulation of granules were not showing interference with the maximum absorption of drug.

3.2. Linearity. The calibration curve of STZ in $0.1 \mathrm{~N} \mathrm{HCL}$ was plotted as shown in Figure 2. The correlation coefficient was found to be 0.997 . These data indicated good linearity of STZ in the range of $2-30 \mu \mathrm{g} / \mathrm{mL}$ as shown in Table 5.

Limit of quantitation (LOQ) is the lowest amount of analyte in a sample that can be determined with acceptable precision and accuracy under stated experimental conditions. The quantitation limit is expressed as the concentration of analyte in the sample. The standard deviation and related standard deviation for the limit of quantitation were well within the desirable limit of no more than $2.0 \%$. The lowest quantifiable concentration was $5.22 \mathrm{mcg} / \mathrm{mL}$ and this parameter can be used for predicting the drug release in low dose formulation. 
TABLE 7: Method precision/repeatability.

\begin{tabular}{lcc}
\hline Sample number & Day 1 & \% cumulative release at 60 min \\
& $\begin{array}{c}\text { Day 2 } \\
\text { Analyst 2 }\end{array}$ & 88.34 \\
1 & 87.09 & 89.23 \\
2 & 86.23 & 87.89 \\
3 & 87.24 & 86.21 \\
4 & 88.78 & 87.47 \\
5 & 87.65 & 87.01 \\
6 & 88.94 & 87.691 \\
Mean & 87.655 & 1.052 \\
Standard deviation (SD) & 1.042 & 1.199 \\
Relative standard deviation (\% RSD) & 1.189 & 87.673 \\
Mean & & 0.999 \\
Standard deviation (SD) & & 1.139 \\
Relative standard deviation (\% RSD) & & \\
\hline
\end{tabular}

TABLE 8: Change in wavelength.

\begin{tabular}{lccr}
\hline Time (minutes) & At 318 & At 320 & At 322 \\
\hline \multicolumn{4}{c}{ Average \% release \pm SD $(n=6)$} \\
0 & 0 & 0 & $83.98 \pm 0.6789$ \\
5 & $8.95 \pm 0.5456$ & $85.12 \pm 0.7678$ & $97.31 \pm 0.8012$ \\
10 & $34.01 \pm 0.4345$ & $98.23 \pm 0.6678$ & $98.12 \pm 0.5612$ \\
15 & $44.25 \pm 0.5987$ & $99.81 \pm 0.8978$ & $99.24 \pm 0.6769$ \\
30 & $66.87 \pm 0.6745$ & $101.29 \pm 0.7809$ & $77.46 \pm 0.8145$ \\
45 & $77.12 \pm 0.7568$ & $76.84 \pm 0.5982$ & $85.76 \pm 0.4568$ \\
60 & $85.93 \pm 0.4768$ & $87.09 \pm 0.3780$ & \\
\hline Average at $60 \mathrm{~min}$ & & $86.26 \pm 0.6744$ & \\
$\%$ RSD at $60 \mathrm{~min}$ & & 0.839 & \\
\hline
\end{tabular}

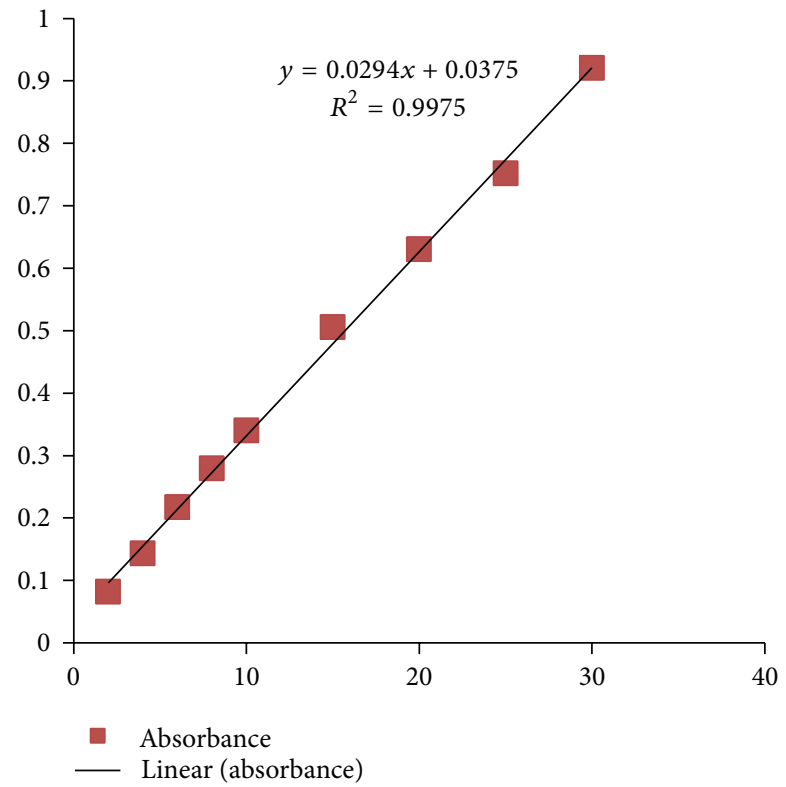

Figure 2: Linearity curve of STZ in $0.1 \mathrm{~N} \mathrm{HCl}$.
3.3. Accuracy. According to USP guidelines, the recovery for a dissolution test must be in the range of 95-105\%. The percent recovery was from $97.21 \%$ to $100.98 \%$. The accuracy of the method is acceptable from the results seen in Table 6.

3.4. Method Precision and Intermediate Precision. The percent RSD did not exceed $2 \%$ for the repeatability and intermediate precision, demonstrating suitable precision. The results are represented in Table 7.

3.5. Robustness. The percent RSD values were within the specified limit of $2 \%$ indicating the robustness of dissolution method on changing the agitation rate and also of UV method by changing the wavelength. The results are shown in Tables 8 and 9.

3.6. Evaluation of Marketed Formulation. By using above optimized dissolution conditions, the dissolution of marketed STZ film coated tablet was performed. The satisfactory $\%$ drug release was obtained at the end of 60 minutes. The results are shown in Table 10. 
TABLE 9: Change in agitation rate.

\begin{tabular}{lccr}
\hline Time (minutes) & At 73 rpm & At 75 rpm & At 77 rpm \\
\hline \multicolumn{4}{c}{ Average \% release \pm SD $(n=6)$} \\
0 & 0 & 0 & 0 \\
5 & $8.98 \pm 0.3987$ & $3.17 \pm 0.5679$ & $8.21 \pm 0.5012$ \\
10 & $35.18 \pm 0.5671$ & $36.93 \pm 0.5712$ & $33.94 \pm 0.6782$ \\
15 & $44.45 \pm 0.6745$ & $42.81 \pm 0.7986$ & $45.24 \pm 0.5867$ \\
30 & $66.23 \pm 0.7681$ & $69.81 \pm 0.6897$ & $66.87 \pm 0.6139$ \\
45 & $76.56 \pm 0.8142$ & $74.26 \pm 0.5893$ & $78.43 \pm 0.7831$ \\
60 & $87.32 \pm 0.4587$ & $88.23 \pm 0.6897$ & $88.42 \pm 0.4879$ \\
\hline Average at 60 min & & $87.99 \pm 0.7633$ & \\
$\%$ RSD at 60 min & & 0.668 & \\
\hline
\end{tabular}

TABLe 10: Dissolution of marketed tablet.

\begin{tabular}{lc}
\hline Time (minutes) & \% cumulative release \\
\hline 0 & 0 \\
5 & $9.34 \pm 0.432$ \\
10 & $28.87 \pm 0.471$ \\
15 & $39.1 \pm 0.572$ \\
30 & $65.43 \pm 0.503$ \\
45 & $83.66 \pm 0.66$ \\
60 & $88.1 \pm 0.55$ \\
\hline
\end{tabular}

\section{Conclusion}

The dissolution test developed and validated for STZ granules was considered satisfactory. The conditions that allowed the dissolution determination were USP apparatus II (paddle) with $0.1 \mathrm{~N} \mathrm{HCl}$ dissolution medium at $37.0 \pm 0.5^{\circ} \mathrm{C}$ rotating at a speed of $75 \mathrm{rpm}$. STZ was found to be stable for $24 \mathrm{hrs}$ indicating good stability of the drug in dissolution medium. The validated method was found to be specific, linear, precise, and accurate. The stated analytical method can be successfully used for in vitro dissolution and routine analysis of samples for STZ granules and also marketed STZ tablets.

\section{Conflict of Interests}

The authors declare that there is no conflict of interests regarding the publication of this paper.

\section{Acknowledgment}

Authors are very much thankful to Dr. P. S. Gide, Principal of Hyderabad Sindh National Collegiate Boards (HSNCB), Dr. L. H. Hiranandani College of Pharmacy, Ulhasnagar, for his continuous support, guidance, and encouragement.

\section{References}

[1] A. Pargal, C. Rao, K. K. Bhopale, K. S. Pradhan, K. B. Masani, and C. L. Kaul, "Comparative pharmacokinetics and amoebicidal activity of metronidazole and satranidazole in the golden hamster, Mesocricetus auratus," Journal of Antimicrobial Chemotherapy, vol. 32, no. 3, pp. 483-489, 1993.

[2] D. M. Parmar and S. P. Jadav, "The concept of personal drugs in the undergraduate pharmacology practical curriculum," Indian Journal of Pharmacology, vol. 39, no. 3, pp. 165-167, 2007.

[3] M. E. Aulton, Pharmaceutics: The Science of Dosage Form Design, Churchill Livingstone, New York, NY, USA, 2nd edition, 2001.

[4] U.S. Department of Health and Human Services, Food and Drug Administration, Dissolution Testing of Immediate Release Solid Oral Dosage Forms, Guidance for Industry, Center for Drug Evaluation and Research (CDER), U.S. Government Printing Office, Washington, DC, USA, 1997.

[5] C. W. Pouton, "Formulation of poorly water-soluble drugs for oral administration: physicochemical and physiological issues and the lipid formulation classification system," European Journal of Pharmaceutical Sciences, vol. 29, no. 3-4, pp. 278-287, 2006.

[6] EPAR, "Acomplia: scientific discussion," European Public Assessment Report EMEA/H/C/666, European Medicines Agency, London, UK, 2006.

[7] M. Zahirul and I. Khan, "Dissolution testing for sustained or controlled release oral dosage forms and correlation with in vivo data: challenges and opportunities," International Journal of Pharmaceutics, vol. 140, no. 2, pp. 131-143, 1996.

[8] "Pharmacopeial previews," Pharmacopeial Forum, vol. 30, pp. 351-363, 2004.

[9] J. W. Moore and H. H. Flanner, "Mathematical comparison of curves with an emphasis on in vitro dissolution profiles," Pharmaceutical Technology, vol. 20, no. 6, pp. 64-74, 1996.

[10] V. P. Shah, Y. Tsong, P. Sathe, and J. Liu, "In vitro dissolution profile comparison-statistics and analysis of the similarity factor, f2," Pharmaceutical Research, vol. 15, no. 6, pp. 889-896, 1998.

[11] “The United States Pharmacopeia," Pharmacopeial Forum USP32 NF-27, 31th edition, 2009.

[12] "ICH harmonized tripartite guideline: validation of analytical procedure Q2A," in Proceedings of the International Conference on Harmonisation (ICH '94), March 1994.

[13] "ICH harmonized tripartite guideline: validation of analytical procedure Q2B," in Proceedings of the International Conference on Harmonisation (ICH '94), March 1994.

[14] L. C. Vaucher, C. S. Palm, A. D. Lange, and E. E. S. Schapoval, "Development and validation of a dissolution test for 
telithromycin in coated tablets," Quimica Nova, vol. 32, no. 5, pp. 1329-1333, 2009.

[15] A. P. Kulkarni, S. Mohd, Z. Zaheer, and M. H. G. Dehghan, "Development and validation of a dissolution method for pioglitazonetablets," Dissolution Technologies. In press.

[16] C. K. Brown, H. P. Chokshi, B. Nickerson, R. A. Reed, B. R. Rohrs, and P. A. Shah, "Acceptable analytical practices for dissolution testing of poorly soluble compounds," Pharmaceutical Technology, vol. 28, no. 12, pp. 56-65, 2004.

[17] C. Noory, N. Tran, L. Ouderkirk, and V. Shah, "Steps for development of a dissolution test for sparingly water-soluble drug products," Dissolution Technologies, vol. 7, no. 1, pp. 16-18, 2000.

[18] M. Siewert, "FIP guidelines for dissolution testing of solid oral products," Pharmazeutische Industrie, vol. 57, no. 5, pp. 362-369, 1995.

[19] "International Pharmaceutical Federation (FIP) guidelines for dissolution testing of solid oral products," Drug Information Journal, vol. 30, pp. 1071-1084, 1996. 

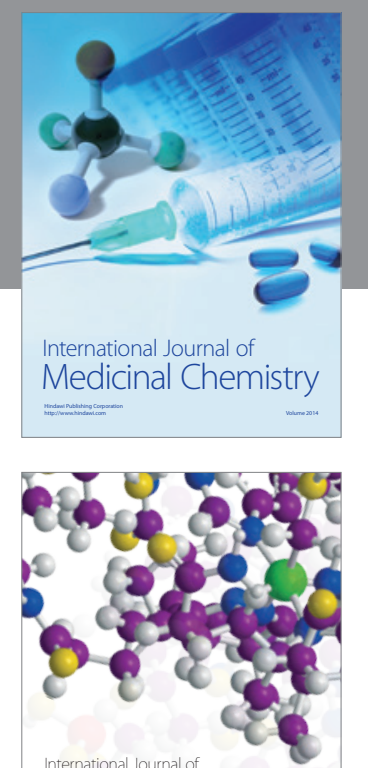

\section{Carbohydrate} Chemistry

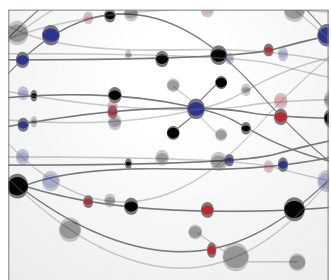

The Scientific World Journal
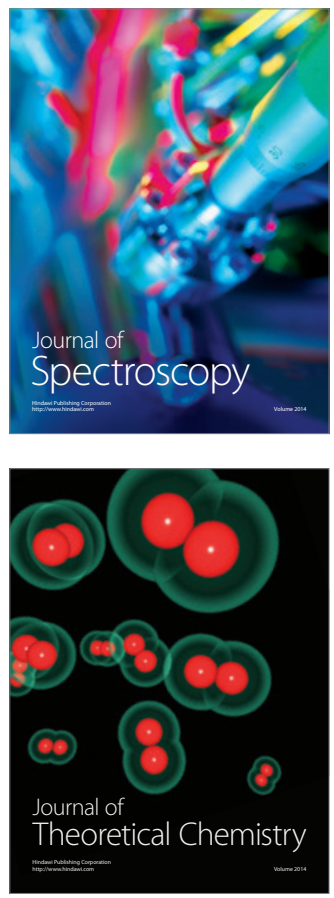
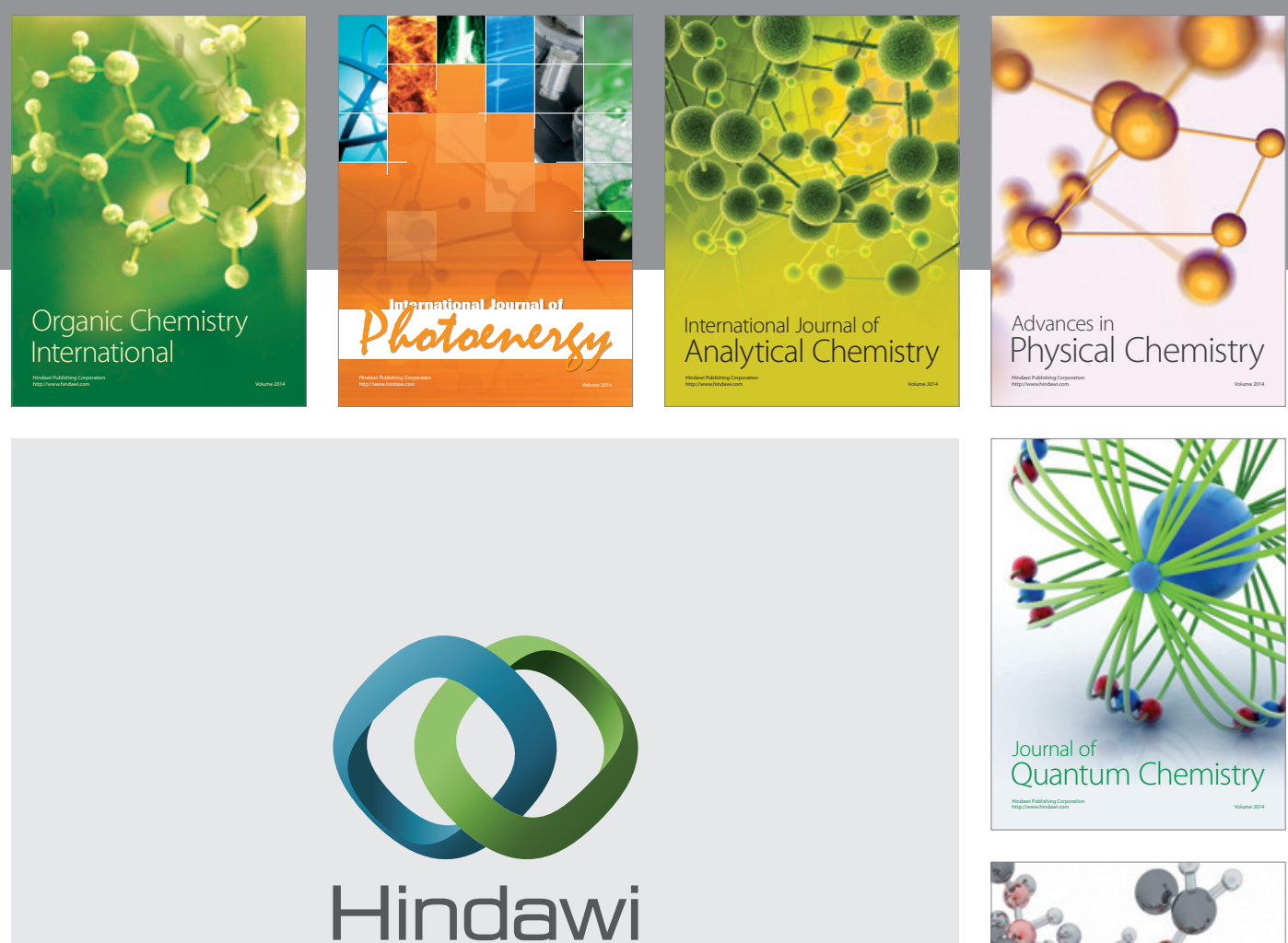

Submit your manuscripts at

http://www.hindawi.com

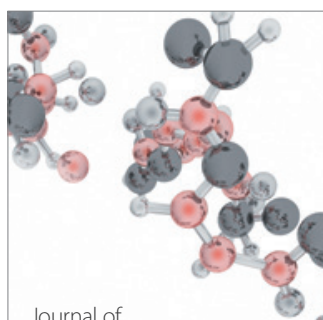

Analytical Methods

in Chemistry

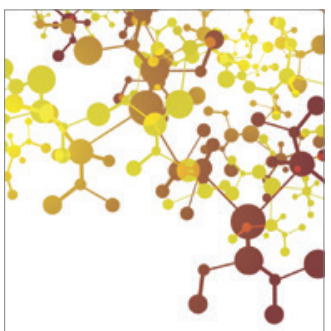

Journal of

Applied Chemistry

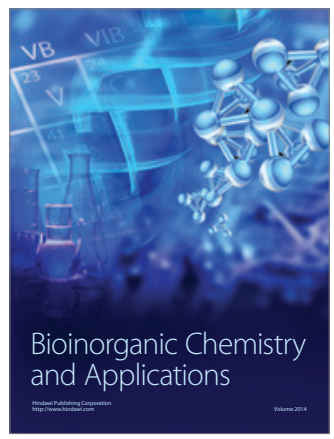

Inorganic Chemistry
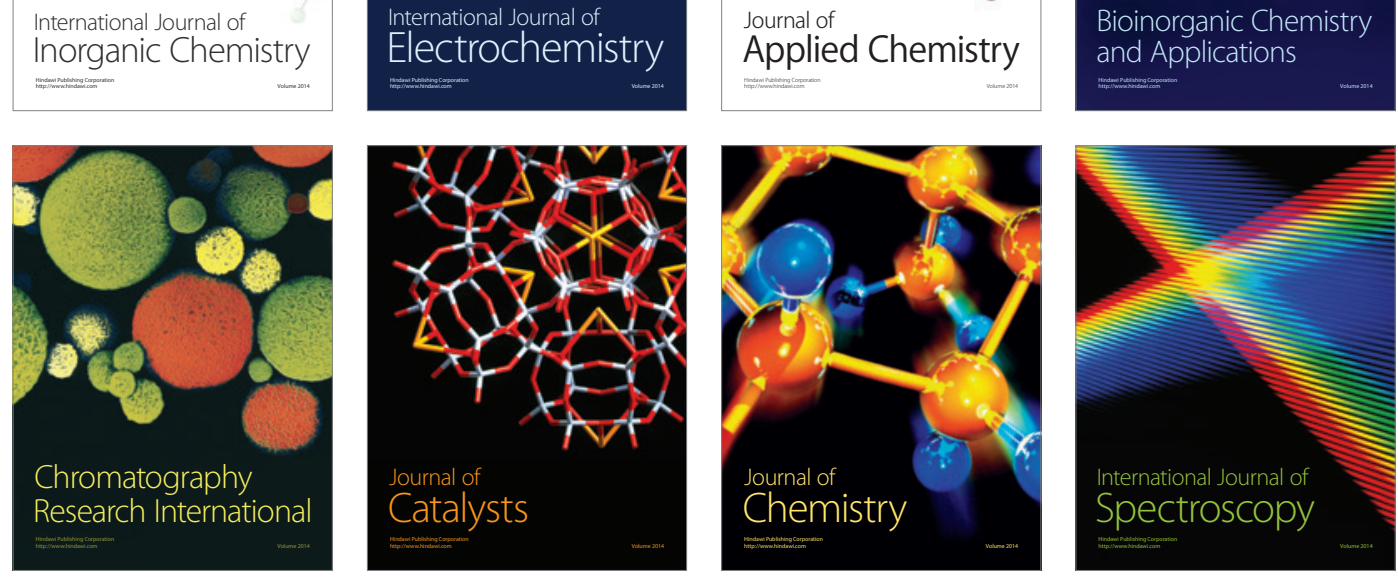